\title{
Chapter 6 \\ Reconsidering Archaeological and Environmental Proxies for Long Term Human-Environment Interactions in the Valley of Kashmir
}

\author{
Michael Spate
}

\begin{abstract}
As response to climate change becomes an ever present issue, considerations of human-environment interactions in the past have moved beyond deterministic notions of climatically driven cycles of social expansion and collapse to more complex examinations of anthropogenic effects upon environments, as well as the transformative effects environmental change has upon human societies. The entanglement between these processes may be explored through a number of theoretical frameworks, including Niche Construction Theory (NCT) and other notions of human resilience. The Valley of Kashmir in the northernmost region of South Asia presents an opportunity for examining a number of these processes. This paper aims to synthesise past archaeological and Holocene palaeoclimate data, as well as review past interpretations of human responses to climate factors in Kashmir. Arguments are raised for new theoretical and methodological approaches to understanding human-environment interactions in the valley, based on recent studies from Kashmir and adjacent regions. These approaches aim to address gaps in understanding arising from poorly resolved environmental records or uncritical integration of archaeological and palaeoclimate data. Some early conclusions may be drawn as to ways in which differentiated land use patterns across the valley and adjacent mountain zones would have allowed for long term patterns of adjustment and reorganisation as a response to climate pressures. New preliminary data that has the potential for exploring some of these processes in the valley is also presented.
\end{abstract}

Keywords Kashmir $\cdot$ Neolithic $\cdot$ Kushan $\cdot$ Climate change $\cdot$ Holocene Niche construction theory (NCT)

\footnotetext{
M. Spate ( $\varangle)$

Department of Archaeology, School of Philosophical and Historical Inquiry, University of Sydney, Sydney, Australia

e-mail: michael.spate@sydney.edu.au

(C) The Author(s) 2019

L. E. Yang et al. (eds.), Socio-Environmental Dynamics along the Historical Silk Road, https://doi.org/10.1007/978-3-030-00728-7_6
} 


\subsection{Introduction}

Situated at the intersection of the Tibetan Plateau, the Indian Subcontinent and Central Asia, the valley of Kashmir has long been considered a temperate, fertile basin between the often unpredictable monsoon driven environments to the south and desert-steppe-mountain regions to the north and east. Due to political disturbances within Kashmir since the 1980s, little archaeological or palaeoenvironmental fieldwork was undertaken for several decades. In recent years, some limited systematic archaeological survey and excavation has taken place (Yatoo 2005, 2012; Mani 2000), leading to publication of new palaeobotanical and archaeological data (Spate et al. 2017; Pokharia et al. 2017). Broader discussions of prehistoric crop dispersals (Stevens et al. 2016; D’Alpoim-Guedes et al. 2014) have situated Kashmir as a node within regional system of agricultural exchange predating the development of the historic Silk Roads. Renewed interest in the Silk Road regions of China, Central and South Asia more generally have placed cultural and economic change into contexts of human-environment interaction, providing new frameworks against which we can consider social and environmental change in Kashmir.

Drawing on a reappraisal of past archaeological and environmental data as well as preliminary analysis of new fieldwork, the following discussion will examine these long term cultural and environmental processes in the valley. Chronological focus will be on the pre-, proto- and early historic periods in the valley, beginning with the Neolithic ca. 3000 BCE, through to the Karkota Dynastic period ending ca. 900 CE. This study begins with a review of the geography of the Kashmir Valley, as well as currently available archaeological and Holocene climate data (Sect. 2). Past interpretive frameworks for human responses to environmental change are discussed in Sect. 3, followed by an examination of recent interpretive palaeoecological frameworks in adjacent regions of South and Central Asia and considerations of how they may be applied to Kashmir. A concluding discussion raises potential new avenues for research in the valley.

\subsection{Valley of Kashmir}

\subsubsection{Geographic and Climatic Context}

The valley of Kashmir is an intermontane basin in the Western Himalayas, the northernmost region of the Indian Subcontinent. Stretching roughly $140 \mathrm{~km}$ north-south and $40 \mathrm{~km}$ across its widest point, the valley is flanked on the eastern side by the Greater Himalaya and on the west by the Pir Panjal ranges. The valley floor generally sits between 1600 and $1800 \mathrm{~m}$ above sea level (ASL), with the peaks of the Pir Panjal rising to around $4500 \mathrm{~m}$ ASL and the Greater Himalaya maintaining a crestline of around $5000 \mathrm{~m}$ ASL. 


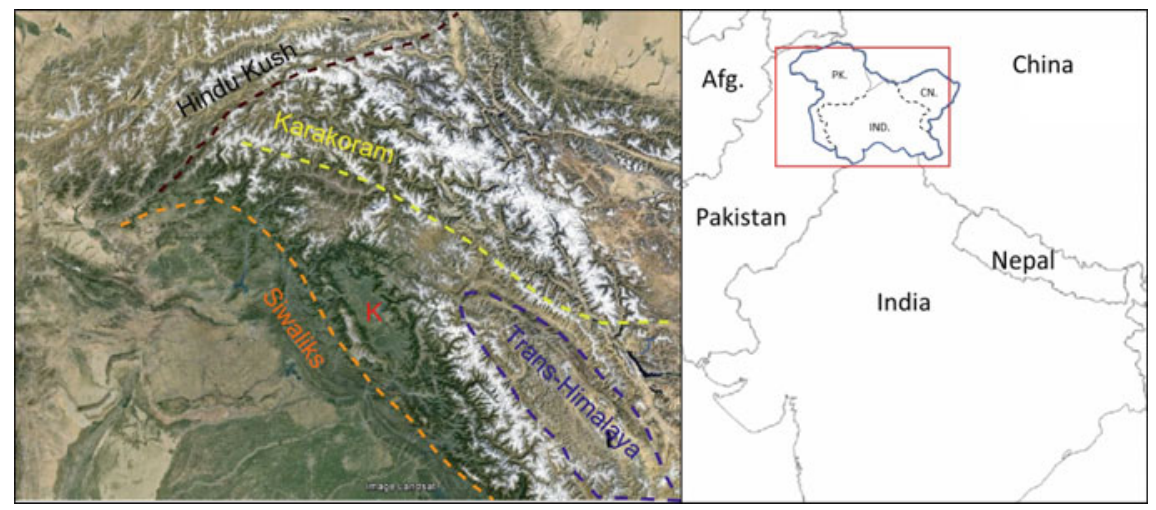

Fig. 6.1 Left-Kashmir valley $(\mathrm{K})$ and surrounding mountain and foothill zones (Landsat, Google Earth). Right—Historic borders of greater Kashmir region and modern military lines of control

To the north and east of Kashmir are the Trans-Himalaya and Karakoram ranges, leading to high altitude steppic-deserts of Ladakh and the Tibetan Plateau (Husain 2008). South of the valley are the Himalayan Siwalik foothills, transitioning to the monsoonal environment of the Punjab forelands. This topography situates the Kashmir valley as a transitional environmental niche between the Indian subcontinent to the south and the mountainous and arid zones of Central Asia and Tibet (Fig. 6.1).

The Kashmir basin was formerly a massive lake, impounded by Pir Panjal orogeny at around 4 million years ago. Ongoing upthrust at around 200 thousand years ago (KYA) drove the water body against the Himalayan flank and began the lifting of lacustrine sediments, known locally as Karewas, on the western side of the valley. The relict landforms of this first phase of Karewa building on the Pir Panjal are grouped as the Lower Karewa formation (Agrawal 1992: 47). From 200 to 85 KYA, aridity driven desiccation and further tectonic activity pushed the lake into the north eastern corner of the valley, leading to the emergence of the younger Upper Karewa sediments. Initiation of loess deposition on the Lower Karewa sediments of Pir Panjal flank began around $300 \mathrm{KYA}$ and on the Upper Karewas from their first emergence ca. 200 KYA (Agrawal 1992: 45). Faulting at the Baramulla gorge in the northwest of the valley at around 85 KYA led to the draining of the lake and the formation of the Jhelum River, as well the final emergence of Upper Karewa sediments on the Himalayan flank (Dar et al. 2014). The lacustrine sediments of the Lower and Upper Karewa and subsequent loessic sequences provide a long term climate archive for the Plio-Pleistocene in Kashmir (Agrawal 1992).

Due to the orographic effect of the Pir Panjal, the Indian Summer Monsoon is effectively blocked in Kashmir leading to a localised humid continental climate (Köppen Dfb), with most precipitation in the form of cold winter rain and snow (Husain 2008: 51). Precipitation is primarily driven by Westerly Disturbances, known locally as Alamgir, between December and April (Kaul 2014: 157). Excessive winter precipitation may be detrimental for Rabi (winter) crops such as wheat and barley, 
though good spring snow melt is crucial for irrigated Kharif (summer) rice agriculture (Husain 2008: 137-139). This bi-seasonal cultivation takes place across the valley in various ecological and topographic niches, with rice typically on the valley floor, smaller fields of wheat and barley on the flanks, and in modern times maize being the dominant middle-high altitude crop of Gujjar nomadic pastoralists.

The distinction between the valley floor, middle and high altitude zones are key for examining variability in economic and cultural adaptations in Kashmir both in the present day and in the past. The valley floor is an alluvial landscape comprised of old and new alluvium, also categorised as river terrace and floodplain soils (Sidhu and Surya 2014: 7). These soils are rich in potassium, phosphorus, calcium and magnesium, and accumulation of nitrogen occurs in significant quantities allowing for high agricultural potential (Qazi 2005: 30). At the margins of the alluvial landscape are flat topped Upper Karewa terraces, known locally as wudur, standing up to $60 \mathrm{~m}$ in height (Husain 2008: 27). Archaeological survey (Yatoo 2012; Bandey 2009) has indicated that Neolithic villages in Kashmir tended to cluster on wudur, likely as a means of mitigating flood risk. This alluvial landscape and associated tablelands form a zone for intensive cultivation and settlement, extending into the mountain foothills to an altitude of around $2200 \mathrm{~m}$ ASL (Kaul 2014: 56).

Between 2500 and $3500 \mathrm{~m}$ ASL are meadows known locally as marg or pathri (Singh 1963), situated within mountain forest belts at middle altitudes, as well as above the timberline. Bhatt (1978) divides these into a high altitude type ca. 3000-3500 m ASL, based on Hirpur clay formations and a lower type based on a silty substratum between 2400 and 3000 m ASL. Agrawal (1992) describes the lower meadow landscapes as being built on the infilling of glacially ground basins and lakes, ideal for environmental coring. Both types of meadow are grazed by flocks of goats and sheep as part of the annual migratory cycle of Gujjar-Bakharwal transhumant groups in the region today (Casimir and Rao 1985).

The ecological diversity in the Kashmir Valley may allow us to conceive of the valley as generally comprised of two ecotopes, being the valley floor and the montane zone. Within these zones are a number of smaller transitional areas (Fig. 6.2), particularly between the forest and meadow communities in the montane zone. More broadly, we may consider the entire valley as a transitional ecotone, situated between the high altitude desert of the Ladakh region, the desert and steppe regions of Central Asia and the sub-tropical regions of the Siwaliks and Punjab to the south, at the interface of Summer Monsoon and Westerly dominated climate zones. The interrelations between various ecotopes and social and economic organisation are argued as primary drivers of cultural and technological exchange in Bronze and Iron Age Central and South Asia (Frachetti 2012; Spengler et al. 2013; Stevens et al. 2016).

\subsubsection{Archaeological and Historical Context}

Early cultural development in Kashmir has primarily been understood through excavations of five pre and proto historic sites, whilst early historic (Kushan and Karkota) 


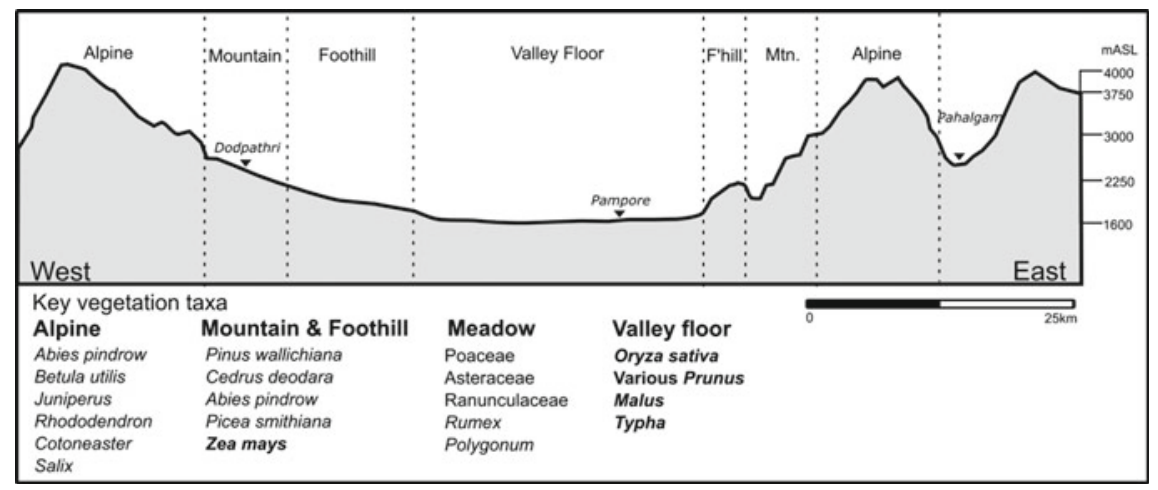

Fig. 6.2 Transverse section across Kashmir valley depicting topographic variation and zonal differentiation. Mid altitude pastures Dodpathri and Pahalgam marked as is Pampore city on the valley floor. Major modern vegetation taxa from each zone is listed, economically important cultivars in bold

periods were also documented in Kashmiri and Chinese historical accounts. A general chronology of cultural changes is presented in Table 6.1.

Excavations at the sites of Burzahom, Gufkral and Kanispura (Fig. 6.3) in the east, south and northwest of the valley have allowed for the development of an archaeological sequence beginning with an Aceramic phase, followed by Early, Late and Megalithic Neolithic periods (Possehl 2002; Sharma 2013; Mani 2000). Though only a small number of absolute dates have been returned from Burzahom and Kanispura (Agrawal and Kharakwal 2002; Pokharia et al. 2017), a fuller sequence from Gufkral is available (Sharma 2013) and a stratified sequence of dates from a surveyed Late Neolithic pit at Qasim Bagh have recently been published (Spate et al. 2017). From these sources, a tentative internal chronology of Neolithic development in the

Table 6.1 General chronology of cultural phases and excavated sites in Kashmir (Agrawal 1992; Bandey 2009; Shali 2001; Spate et al. 2017; Yatoo 2012)

\begin{tabular}{l|l|l}
\hline Period & Date range & Sites \\
\hline Karkota & $600-900 \mathrm{CE}$ & Semthan \\
\hline Hunnic & $300-600 \mathrm{CE}$ & Kanispura, Harwan \\
\hline Kushan & $1-300 \mathrm{CE}$ & Kanispura, Semthan, Harwan \\
\hline Indo-Greek & $200 \mathrm{BCE}-1 \mathrm{CE}$ & Semthan \\
\hline NBPW & $700-200 \mathrm{BCE}$ & Semthan \\
\hline Megalithic & $1500-700$ BCE & Burzahom, Gufkral, Semthan \\
\hline Late Neolithic & $2000-1500$ BCE & Burzahom, Gufkral, Qasim Bagh \\
\hline Early Neolithic & $2500-2000$ BCE & Burzahom, Gufkral, Kanispura \\
\hline Aceramic Neolithic & $3000-2500$ BCE & Kanispura, Gufkral \\
\hline
\end{tabular}




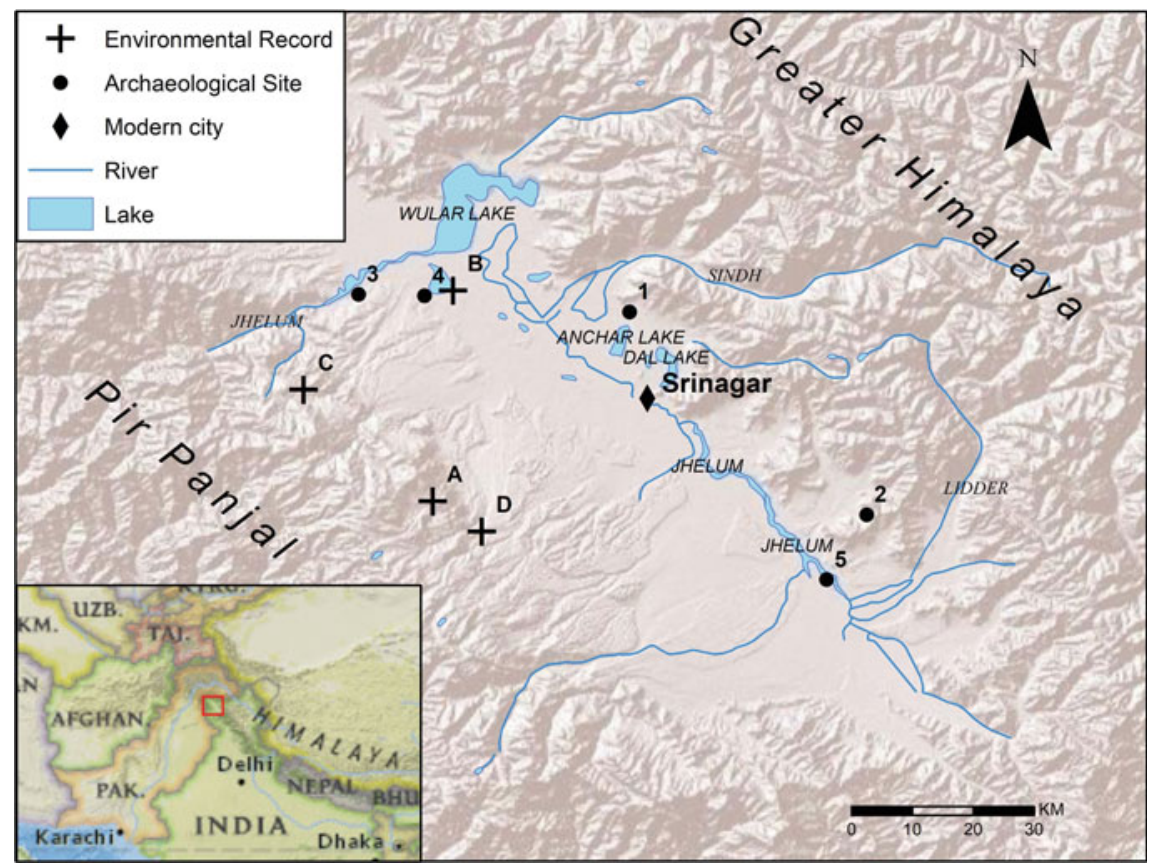

Fig. 6.3 Archaeological sites and environmental cores discussed in text. Sites: 1. Burzahom \& Harwan; 2. Gufkral; 3. Kanispura; 4. Qasim Bagh; 5. Semthan. Cores: A. Toshmaidan; B. Hygam; C. Butapathri; D. Pari-Has (Basemap source: ESRI)

valley may be conceived as: Aceramic Neolithic 3000-2700 BCE; Early Neolithic 2700-2000 BCE; Late Neolithic 2000-1500 BCE; Megalithic 1500-700 BCE.

Change in material culture through the Neolithic is relatively conservative, beginning with a ground stone lithic industry during the Aceramic (Pant et al. 1982), the use of which continues throughout the cultural sequence. During the Late Neolithic polished stone harvesters are introduced comparable to types from the Yangshao Neolithic of China, leading to speculation of cultural connections with North Asia (Possehl 2002). The ceramic sequence begins with coarse ware cooking pots during the Early Neolithic, with later introductions of fine and burnished wares. During the Megalithic, a gritty red ware is introduced (Yatoo 2012). Structural remains consist of subterranean rectangular dwellings with a timber superstructure in early periods, followed by rammed earth platform buildings during later phases (Sharma 2013). Throughout the Neolithic, large conical pits up to $3 \mathrm{~m}$ deep were dug, the use of which is subject to ongoing debate (Conningham and Sutherland 1997; Young 2003; Bandey 2009).

Analysis of botanical (Lone et al. 1993; Spate et al. 2017; Pokharia et al. 2017) and faunal (Sharma 2013) remains seems to indicate the early economy during the Neolithic was based upon hunting and cultivation of winter barley and wheat. A later shift towards consumption of domestic animals and the introduction of rice and millet 
may be interpreted as a shift towards bi-seasonal cropping, and the development of a herding economy.

Later cultural phases are represented at the site of Semthan in the southeast of the valley. Little excavation data has been formally published and most information is gleaned from annual reports (Thapar 1980; Mitra 1983) and a systematic botanical study (Lone et al. 1993). The sequence begins with a phase comparable to the Megalithic (ca. 1500-700 BCE) at Burzahom and Gufkral (Semthan Phase I), whilst subsequent phases represent the first changes in material culture linking Kashmir to the rise of Iron Age urbanism on the Indian Subcontinent. Phase II (ca. 700-200 BCE) is analogous to the Northern Black Polished Ware (NBPW) culture of South Asia, whilst Phase III (ca. 200 BC-1CE) represents an Indo-Greek period. The Kushan period is represented by Phase IV (1-300 CE), whilst Phase V (600-900 CE) is considered contemporary with the "prolific temple building" period of the Hindu Karkota Dynasty (Mitra 1983: 23). The Kushan period is also evident in temple and settlement remains at Kanispur (Mani 2000; Pokharia et al. 2017) and temple structures at Harwan in Srinagar (Kak 1933). Post-Kushan period remains (ca. 300-600 CE) at Kanispura and Harwan have been interpreted as evidence of incursion by Central Asian Hunnic nomads (Shali 2001).

Botanical macro remains from Semthan indicate a shift towards summer rice and millet agriculture during all phases, and also sees the introduction of several South Asian summer pulses such as Vigna mungo, Vigna radiata, and Vigna acontifolia (Lone et al. 1993: 209-212). Lone et al. (1993) have argued that despite this broadening of the agricultural package, the thinness of the archaeological deposits of the NBPW and Indo-Greek phases, coupled with a declining diversity index of wood charcoal at the site indicates some form of population collapse during this period.

It is unclear whether the Kushan period represents a population recovery following collapse as interpreted by Agrawal and Lone et al., or rather represents the first major archaeological evidence for social reorganisation and intensified urban settlement in Kashmir. Excavation data from the pre and proto historic periods suggest evidence for both economic diversity and horizontal social complexity, whilst the Kushan period may be the first instance of development of vertical complexity and state building in the valley. These institutional changes would shift the opportunities and constraints for responses to climate or demographic pressure in the valley, processes that would have continued through the Karkota period. Bamzai (1994) has also argued that the Karkota period was a time of major institutional realignment, with an expansion of bureaucracy, intensification of public works including major irrigation systems and centralisation of social responses to environmental calamity. This period also saw a political re-orientation towards China against the backdrop of the decline and fall of the Sassanian and Gupta Empires in Greater Iran and India. 


\subsubsection{Holocene Palaeoclimate}

The earliest paleoclimate studies in Kashmir tended to focus on glacial cycles and Pleistocene vegetation changes in Lower Karewa sediments (De Terre and Paterson 1939). Holocene climate reconstruction was first undertaken by Singh (1963), producing a post-glacial vegetation sequence from a high altitude peat bog at Toshmaidan in northwest Kashmir. Singh identifies 8 pollen zones and 9 stratigraphic sections, which were dated through later re-excavation and sampling of bedding planes (Singh and Agrawal 1976). These dates have been recalibrated and presented in Table 6.2 alongside Singh's original phasing.

Singh (1963: 103) uses broad leaf/coniferous (B/C) ratios as an index of postglacial warming and cooling, finding correlation between the advance of broad leaved and thermophilic non arboreal taxa, most notably in Stages b, d and e. Despite the return of Pinus dominance in Stage c, Singh interprets Stages a-e as a postglacial amelioration with a climatic optimum during Stage e. Dating of this stage remains problematic due to poor correlation between the initial pollen study and later resampling to date the column (Singh and Agrawal 1976). Vishnu-Mittre (1966; Vishnu-Mittre and Sharma 1966) has argued the three warm phases of Toshmaidan stages $b, d$ and e correlate with other past thermophilic vegetation stages in an undated sequence at Haigam on the valley floor, positing a succession of post glacial warming and cooling directly comparable with the European Blytt-Sernander pre-Boreal to sub-Atlantic phases.

Two high altitude pollen records from peat bogs at Butapathri-I and ButapathriII (3000 m ASl) attempted to refine the chronology of the Toshmaidan sequence (Dodia 1983). The first record is argued to be evidence advance of broad leaf species over conifers from around 18,000-15,000 BP, indicating an early period of climatic amelioration following the last glacial maximum (Agrawal 1988). This broad leaf advance is also synchronous with strong formation of paleosols throughout the valley (Kusumgar et al. 1986). A warm wet phase at $18 \mathrm{Kya}$ is indicated by $\delta^{13} \mathrm{C}$ ratios from Paleosol 1 at Burzahom, where a ratio of $-25.3 \%$ indicates strong dominance of warm wet favouring C3 plants, which contrasts clearly with C4 dominance in the organic fraction of earlier buried paleosols (Krishnamurthy et al. 1982). The record at Butapathri-II gives a sequence dating back to ca. 12 K BP (Dodia 1983). Both records seem to indicate the onset of thermophilic Juglans, Carpinus, and Corylus broad leaved taxa at around $5000 \mathrm{BP}$, again roughly synchronous with the start of the Neolithic period. Reconstructing a well resolved chronology from these records presents some difficulty due to bulk organic dates being taken from samples up to $50 \mathrm{~cm}$ in length, and these records may best serve generally refining the cooldry/warm-wet phases in the valley.

Later Holocene climatic records have been reconstructed through pollen sequences from lower altitude lakes at Anchar and Horkasar (Dodia 1983; Agrawal et al. 1989), dating to $4000 \mathrm{BP}$ and $1000 \mathrm{BP}$ respectively (Agrawal et al. 1989). Anchar is characterised by the dominance of grasses interpreted as cereals in the NAP curve, with Pinus/broad leaf fluctuations in the arboreal pollens. An anti- 


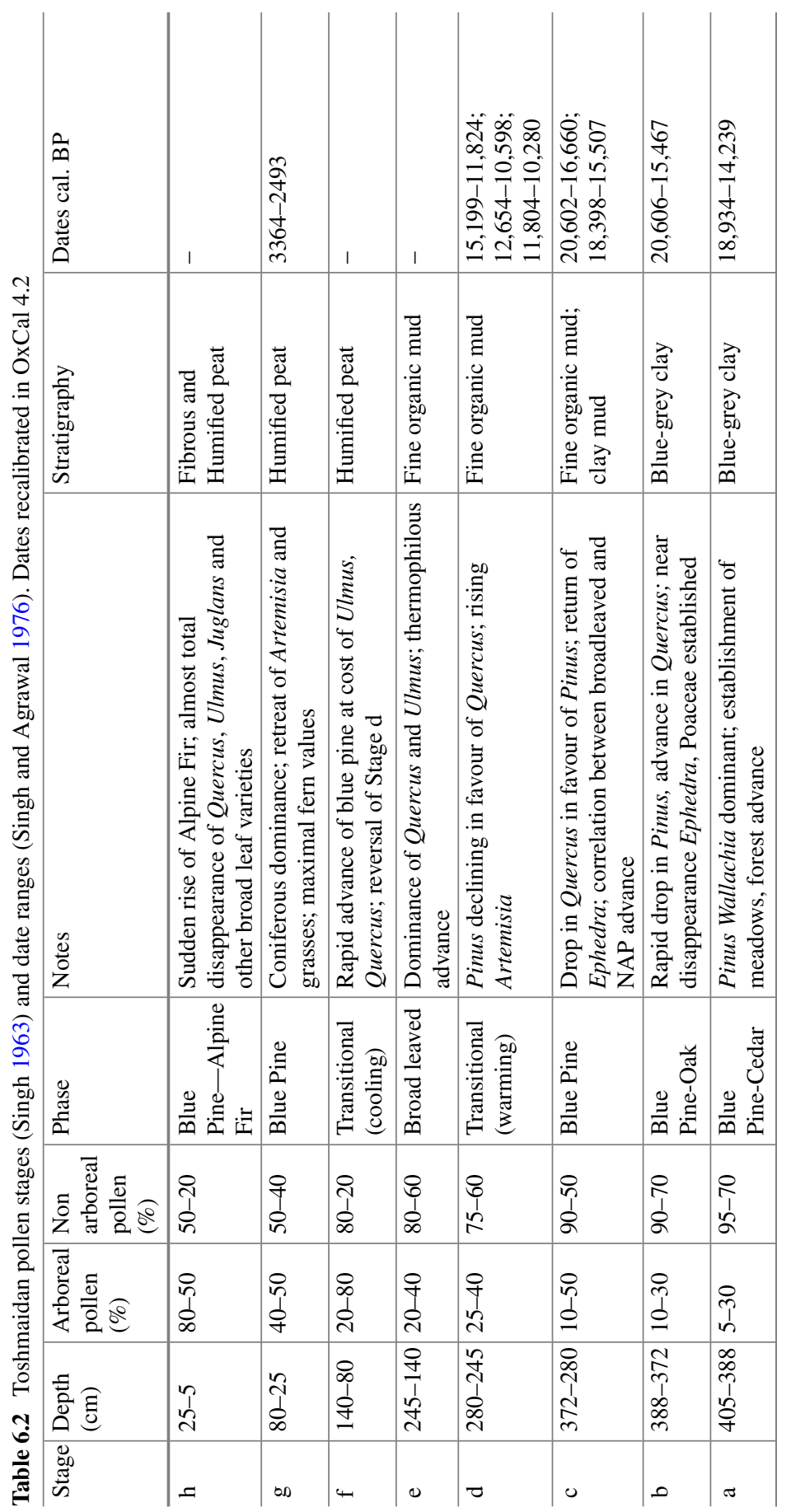


correlation between anthropogenic plants and aquatics suggests the reclamation of farming land at lake margins on the valley floor. A similar relation anti-correlation is found at $800 \mathrm{BP}$ in the Horkasar core, which Agrawal et al. (1989) believe to be evidence for the beginning of intensive rice paddy cultivation. Fluctuations in anthropogenic crops against a background climate index based on $\mathrm{B} / \mathrm{C}$ ratios may allow for an understanding of ecological responses to climate change, however complete data sets from these records remain unpublished.

Agrawal (1988: 339) notes the early post glacial warming in Kashmir may be correlated with pollen records from Nepal and Japan, and suggests the possibility of a latitudinal climatic belt. As Agrawal (1988: 340) also describes an inverse correlation between Kashmiri and lowland North Indian records, the orographic effects of the Pir Panjal and Tibetan plateau on the paleoclimate of Kashmir may be a dominant factor in influencing local and regional conditions. The regionally out of synch climate proposed by Agrawal seems to be supported by comparison of the Kashmir records with pollen, isotopic and geochemical records from the Siwalik foothills to the south (Trivedi and Chauhan 2009; Das et al. 2010) and the TransHimalayan and Ladakh regions to the northeast (Rawat et al. 2015; Leipe et al. 2014; Demske et al. 2009). A comparison of shifts in climate between Kashmir and adjacent regions (Table 6.3) reflects more frequent onsets of optimal conditions and transitional periods in the valley than the protracted cold dry desert conditions of the Trans-Himalaya or fluctuations in monsoonal periods of the Siwaliks.

The apparently regionally asynchronous climate shifts in Kashmir have allowed for some scholars to conceptualise cultural change in the valley as driven by fluctuations between warm-wet and cool-dry cycles, treating the valley as a climatically optimal ecological refuge between the steppe-desert and monsoonal systems of surrounding areas (Agrawal 1988, 1992; Shali 2001). In these schemes, the Neolithic, Kushan and Karkota periods map neatly onto warm wet periods (Table 6.3), interspersed with periods of cultural or societal degradation. Whilst these may be useful interpretations in a broad sense, they are complicated by the poorly resolved chronology of climatic records and gaps in knowledge of the economy, ecology and social organisation during large parts of these cultural phases. Taking into regard the variability of environmental zones within the valley and what is known from archaeological and palaeoclimatic records, we are presented with the opportunity to produce an integrated model for understanding long term human-environment interaction in Kashmir.

\subsection{Human-Environment Interaction in Kashmir}

\subsubsection{Previous Studies}

Early examinations of the interrelation between climate change and human activity in Kashmir were raised by De Terre and Paterson (1939: 233-235), critiquing 
the provenance of artefacts previously believed to be Palaeolithic and arguing that human habitation of the valley most likely became possible as a response to warmer conditions of the Holocene. In this interpretation, late Palaeolithic hunters colonised the valley in the pursuit of new game, before taking up agriculture. Despite raising these question, much of their work was dedicated to glacial cycles and climate change operating at time scales longer than human occupation of the valley.

Subsequent studies drew upon the interpretation of anthropogenic markers in pollen records. Singh (1963) ascribes some changes in the Toshmaidan record to deforestation during the migration of Aryans and Indo-Greeks, grazing by Central Asian pastoralists and large scale works during the Mughal period, however the impacts and timing of these are not clearly articulated. Vishnu-Mittre (1966) has argued that the pollen record from Toshmaidan provides little to no evidence for human impact on the environment, in contrast with the Hygam record with some indicators of agricultural intensification, based on fluctuations in the pollen curves of cereal grasses and Plantago lanceolata. Vishnu-Mittre and Sharma (1966: 206) describe the Hygam records as having four anthropogenic phases: the commencement of agriculture; low level cultivation; intensification of agriculture; and decline. Notably, the decline corresponds with the end of Hygam pollen Stage e, marked by an increase in coniferous species interpreted as evidence for regional cooling. Vishnu-Mittre and Sharma argue that agricultural intensification corresponds with

Table 6.3 Comparative chronology of Kashmir climate and cultural phases with regional climate shifts (Kashmir records: Singh 1963; Dodia 1983; Agrawal 1992. Siwaliks: Trivedi and Chauhan 2009; Das et al. 2010. Trans-Himalaya: Rawat et al. 2015; Leipe et al. 2014; Demske et al. 2009)

\begin{tabular}{|c|c|c|c|c|}
\hline Cultural Periods & YBP & Kashmir & Siwaliks & Trans-Himalaya \\
\hline \multirow{2}{*}{ Historic } & 500 & Cool Dry & Cool Dry-Ameliorating & Cool Dry-Ameliorating \\
\hline & 1000 & Warm Broad Leaf dominance & & \multirow{5}{*}{ Cold Dry } \\
\hline Karkota & 1500 & Transitional - Cooling & & \\
\hline Kushan & 2000 & Warm Broad Leaf dominance & & \\
\hline NBPW/Indo-Greek & 2500 & Cool Dry & Cool Dry & \\
\hline Megalithic & 3000 & & & \\
\hline Ite Nelithic & 3500 & Transitional - Cooling & & \multirow[b]{2}{*}{ Transitional-Cooling } \\
\hline $\begin{array}{l}\text { Late Neolithic } \\
\text { Early Neolithic }\end{array}$ & $\begin{array}{l}4000 \\
4500\end{array}$ & \multirow{2}{*}{ Holocene Optimal } & & \\
\hline \multirow[t]{11}{*}{ Aceramic Neolithic } & 5000 & & \multirow{3}{*}{ Warm Broad Leaf dominance } & \multirow{3}{*}{ Holocene Optimal } \\
\hline & 5500 & \multirow{5}{*}{ Cool Dry } & & \\
\hline & $\begin{array}{l}6000 \\
6500\end{array}$ & & & \\
\hline & 7000 & & Cool Dry & \multirow{2}{*}{ Transitional - Warming } \\
\hline & 7500 & & \multirow{3}{*}{ Warm Broad Leaf dominance } & \\
\hline & $\begin{array}{r}8000 \\
8500\end{array}$ & & & $8.2 \mathrm{k}$ Cold Event \\
\hline & 9000 & \multirow[t]{2}{*}{ Transitional-Cooling } & & \multirow{3}{*}{ Cool Dry } \\
\hline & $\begin{array}{c}9500 \\
10000\end{array}$ & & \multirow{4}{*}{ Records unavailable } & \\
\hline & 10500 & \multirow[t]{2}{*}{ Warm Broad Leaf dominance } & & \\
\hline & 11000 & & & \multirow[b]{2}{*}{ Warm Wet } \\
\hline & $\begin{array}{l}11500 \\
12000\end{array}$ & Transitional - Warming & & \\
\hline
\end{tabular}


the Holocene optimum during the Neolithic period and subsequent contractions are again evidence of a climate driven societal collapse. These interpretation are problematised by the lack of absolute dates from the Hygam record.

The Kashmir Palaeoclimate Project (KPCP) was initiated in the early 1980s before being interrupted by rising militancy in the valley. In addition to documenting the first securely dated Upper Palaeolithic in the valley at around 18 kya (Pant et al. 1982), the project revised produced new chronological, palynological, isotopic and geological data. A synthesis of these studies (Agrawal 1992) argued for expansions of settlements and population expansion in the valley during warm wet periods of the Upper Palaeolithic, Neolithic, Kushan and Karkota periods, as evidenced by the spread of Neolithic villages, and later, monumental constructions throughout the valley during climatic ameliorations. Agrawal (1992: 271) argues that settlement expansion and population growth during these periods led to Malthusian pressures precipitating societal collapse when average temperatures declined by one to two degrees during periods of cooling.

Drawing on historical accounts, and KPCP and archaeological datasets, Shali (2001) interpreted culture change in Kashmir as a unilinear sequence of cultural development, following Agrawal's (1992) scheme of acceleration during optimal conditions and slowing during cold dry periods. Shali integrates some discussion of economic changes during these periods, attributing the expansion of agriculture and animal husbandry to ongoing increases in social complexity allowing for the division of labour and the importation of new crop species as part of regional trade intensification. Shali (2001: 134) has also argued for regional climate change as a driver of migrating Central Asian tribes, forcing them into closer contact with Kashmir due to the more favourable climate of the valley. These demographic influxes are argued to have contributed either to fragility of social structures during climatic deteriorations (Shali 2001: 129), or accelerated technological and cultural change and synthesis during optimal conditions (Shali 2001: 182).

The interpretive frameworks of the studies above are closely tied to notions of environmentally driven societal collapses that have been subject to reappraisal in recent archaeological literature (McAnany and Yoffee 2009; Faulseit 2015). Common to collapse oriented studies are varying degrees of human-induced stresses on environments, or global and regional climate change as the primary forcing factors of historical transformation (Middleton 2012). Yatoo (2012) has argued that interpretations such as this arise partly as the result of site-centric archaeological studies in Kashmir and ad hoc correlation with often poorly resolved climate data, evident in such assumptions as the presence of monumental construction during the Kushan and Karkota periods as periods of wealth and stability interspersed with periods of climate driven hardship. Scott (2017) has argued that archaic states, rather than populations as a whole, are particularly susceptible to climate change, and that the absence of large archaeological monuments during periods previously interpreted to be phases of "collapse" may simply be evidence for the breakdown of coercive forces able to centralise labour for such large scale constructions. Yatoo's (2012) landscape oriented studies in northwest Kashmir may present early evidence for social reorgan- 
isation, and dispersed and adaptive patterns of land use in the valley, though further archaeological testing and excavation is required to better understand these changes.

Resilience to acute or protracted climate change in South Asia has been examined through shifts in cropping pattern that allowed Indus Valley populations to cope with environmental diversity and stresses in prehistoric northern South Asia (Petrie et al. 2017). Changes in water management, crop selection and settlement pattern have opened new debate onto the ways that Harappan populations responded to climate episodes such as the $4.2 \mathrm{k}$ event, shifting discussions from one of collapse following the Mature Harappan period to reconsidering the post-urban Late Harappan as an adaptive settlement strategy rather than necessarily a period of collapse. Young (2003) has modelled long term economic and social adaptation across multiple environments in the valleys and lowlands of northwest Pakistan. Drawing on botanical and faunal remains as well as environmental, archaeological and ethnographic evidence for shifting patterns of seasonal pastoral mobility, sedentism and cultivation, Young argues for complex and shifting relationships between Bronze and Iron Age agropastoralists, their environment and adjacent regions of China, Kashmir and Central Asia (Young 2003). These multi-proxy studies may provide the best avenue to build more robust new models of past human-environment relationships in Kashmir.

\subsubsection{Kashmir as Ecological Niche}

Based on the geography and climate of Kashmir described in Sect. 2, we may consider the valley to be an orographically circumscribed entity comprised of smaller ecological zones. Though the valley has long been culturally and ecologically enmeshed with adjacent regions, the enclosing topography allows for well-defined spatial constraints for testing hypotheses relating to human-environment interactions. We may consider Kashmir as a fertile and temperate niche, attractive for various forms of settlement, cultivation and resource exploitation (Agrawal 1992; Shali 2001; Bandey 2009). Whilst these naturally occurring conditions may have been a factor in initial settlement of the valley, anthropogenically induced environmental stresses and opportunities in the valley were likely major drivers of social change.

Niche Construction Theory (NCT) originates in evolutionary biology, emphasising the ability of organisms to partially direct their own, and other species evolutionary pathways through the modification of the dwelling niches in which they exist (Laland and O'Brien 2010). Laland and O'Brien (2010) have argued that due to the capacity Homo sapiens have for intergenerational cultural and technological transfer, human niche construction is unique in its potency for directing the evolution of human and other species. Examples of this may include the ways that dietary patterns relating to hunting and gathering, agriculture or pastoralism may have impacted both human genetic evolution in terms of the capacity to process starch or lactose, and the evolution of cultivated crops or domestic animals. As opposed to dichotomous relationships of co-evolutionary frameworks such as host-parasite, predatorprey, herbivore-plant, Laland and O'Brien (2010: 311-312) stress that NCT may 
be conceived of as a broader network of indirect evolutionary linkages that may be recognisable archaeologically.

Responding to debates pushing for a global Anthropocene beginning in the 20th Century, archaeologically focused scholars argue that human niche construction has impacted environments and species distribution globally since the Late Pleistocene (Boivin et al. 2016). Of four key phases of human niche construction identified by Boivin et al. (2016), two are particularly useful for examining human-environment relations in the Kashmir Valley, the first being the spread of agriculture and pastoralism, during which a number of domesticated plants and animals, alongside other commensal species, dispersed across the globe. The second phase is the subsequent development of urbanism and elaboration of trade networks during which intensified patterns of land usage, cultural exchange and overexploitation of resources began to take place. Ellis et al. (2017) list several archaeologically and geologically visible proxies of niche construction by agrarian societies, including anthrosols and degraded soils, deforestation and permanent fields, all of which may be detected in Kashmir.

In addition to detecting landscape modification by cultivators, Spengler (2014) has argued for NCT as an informative framework for understanding practices of Central Asian pastoral groups during the Bronze (ca. 2500-500 BC) and Iron Ages (500 BC-AD 500). Contra to past views that nomadic or transhumant pastoralists simply inhabited ecological niches, Spengler argues for long term processes of intentional landscape modification as a cultural and economic strategy, visible through environmental markers for deforestation and suppression of woody taxa in favour of herbaceous colonists associated with grazing, most commonly Chenopodium species. Miehe et al. (2009) have also argued that this phenomenon is visible in changes in the pollen spectrum in Tibet, where pollen and micro charcoal indicators for mid-Holocene deforestation and grazing fluctuate independently of isotopic and geochemical records displaying no evidence of pasture management, tying into wider debates on the ways that economic adaptation may have allowed humans to colonise the Tibetan Plateau. These case studies provide a method for detecting pastoralist niche construction in Kashmir.

\subsubsection{Conceptualising Long Term Human-Environment Interaction in Kashmir}

The framework proposed in this paper aims to draw on multiple lines of archaeological and environmental data to model both human responses to environmental or climatic changes in the valley, and human modification of the valley itself. Based upon differentiated geographical and topographical zones within Kashmir, long term human ecology may be characterised through shifting patterns of settlement, economic and cultural organisation across the alluvial valley floor (1600-1800 m ASL), Karewa tablelands and foothill zone (1800-2200 m ASL), mountain (2200-3000 m 
Table 6.4 Framework for modelling local and regional scale human activities in Kashmir valley, including potential archaeological and environmental proxy evidence. Local scale dynamics are bridged across topographic zones by regionally controlling social, political and climatic factors

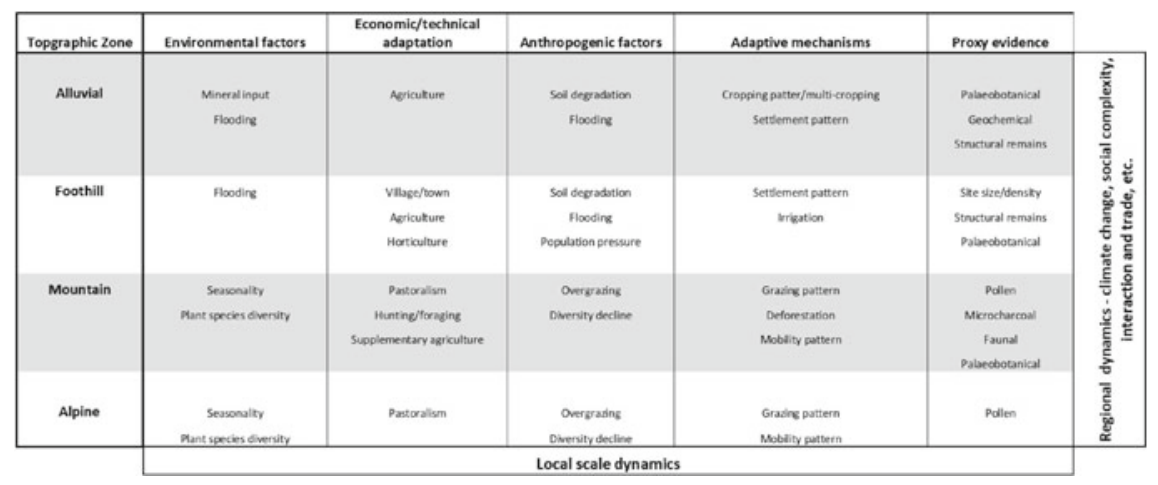

ASL) and alpine (3000-4000 m ASL) zones. Though certain activities in each of these zones may be geographically constrained, they do not operated as discrete units and are integrated into a dynamic, valley wide network (Table 6.4). Certain social or environmental factors may influence these activities at local scales (Table 6.4, $\mathrm{x}$-axis), whilst also being subject to shifting climatic, cultural or political dynamics at regional or extra-regional scales (Table 6.4, y-axis). Regional factors may include broad climate shifts as described by Singh (1963) and Agrawal (1992), the interaction of Kashmir with prehistoric networks of pastoral and agricultural exchange (Stevens et al. 2016), or cultural integration with prehistoric cultural complexes (Yatoo and Bandey 2014) and later systems of imperial control (Shah 2013).

Modelling local scale dynamics across the valley requires consideration of the appropriateness of specific proxy evidence and the ways these datasets may be interpreted to separate regional scale changes from local human-environment interactions. Such interpretation may be reasonably uncomplicated in the cases such as long term studies of relatively stable archaeological features, though may become more problematic when trying to resolve small scale human activities in long term environmental archives.

\subsubsection{Settlement Pattern}

The first systematic field survey of settlement pattern in relation to ongoing social process and environmental change in Kashmir was undertaken by Yatoo (2012) in the Baramulla District in the northwest of the valley. Yatoo's work aims to integrate long term settlement stability and change with other shifts in resource utilisation and cultural interactions. Despite the fact that the study examined only surface features, settlements seemed to vary topographically through time, and multi-period sites were in the minority of those recorded (Yatoo 2012: 197). Yatoo's data shows that during 
the Neolithic period, settlements typically clustered on Karewa table tops above the Jhelum floodplain, around or above $1600 \mathrm{~m}$ ASL. All surveyed Neolithic sites were within a single size category of 7500-9000 $\mathrm{m}^{2}$. In subsequent protohistoric and historic periods, there is a greater diversity of altitudinal distribution and settlement density. Yatoo attributes these changes to broadening resource utilisation, including paddy cultivation within the floodplain and grazing in mountain zones, as well as responses to climatic shifts, such as fluctuation in river and lake levels on the valley floor.

Conningham and Sutherland (1997) and Young (2003) have also raised questions of seasonal settlement pattern during the early Neolithic periods. Subterranean conical structures during this period were traditionally believed to be winter habitation pits (Bandey 2009). Reassessing these structures in the Kashmir and Swat Valleys, Conningham and Sutherland argue for food processing or other non-habitational uses of the pits, the nature of winter dwellings in the valleys. This has been explained through the possibility of seasonal pastoralism and wholesale abandonment of settlements in the valley during winter (Conningham and Sutherland 1997: 32), perhaps as part of a seasonal pastoral migration. Seasonal mobility may be one explanation for variation in settlement patterns that goes beyond growth and contraction settlement and climate cycles, as it may allow for some flexibility in response to climate pressures, from short term to long term scales. Despite the appeal of this model, there is yet little other evidence for wholesale movements of populations out of the valley, and from the Neolithic onwards the seasonal growth cycles of certain crops within archaeobotanical assemblages suggests a tendency to year long occupation in the valley.

\subsubsection{Agricultural Adaptations}

The Early Neolithic botanical assemblage from four phases at Kanispura provides the first insights into agriculture in the valley. The oldest plant remains at the site are dated relative to c. $2700 \mathrm{BC}$, with wheat and barley grains from a later phase directly dated c. 2200 BCE (Pokharia et al. 2017). The overall assemblage is dominated by barley (Hordeum vulgare) with smaller amounts of emmer wheat (Triticum dicoccum), compact wheat (T. cf. aestivum) and a large proportion of lentil (Lens culinaris). The composition of this assemblage is comparable to contemporary sites situated to the west of Kashmir, including Sheri Khan Tarakai (Thomas and Cartwright 2010), Mehrgarh (Costantini 1981) as well as at southern Central Asian sites including Jeitun (Harris 2010) and Anau (Miller 1999). Costantini (2008) describes these early periods of farming at Mehrgarh as developing prior to specialisation of agriculture and selective cultivation of crops. This protracted transition to agriculture in South Asia occurs through shifting relationships between cultivation, sedentism and pastoralism (Murphy and Fuller 2016). Though there is not yet any recorded evidence for early sedentism or cultivation at during the Aceramic phase at Kanispur, the presence of stable settlement structures and agricultural crops at the slightly later dated Gufkral Aceramic (Sharma 2013) raises possibility for their discovery in the future. 
The Aceramic period at Gufkral is also characterised by cultivation dominated by barley, followed by smaller proportions of wheat, lentil and pea (Sharma 2013: 103). During the Early Neolithic wheat becomes the dominant crop, and rice introduced during the Late Neolithic, becoming the primary crop by the Megalithic. These changes in consumption patterns are comparable to the Neolithic botanical assemblages from Burzahom, from the Early Neolithic onwards, though rice never comes to dominate the assemblage as at Gufkral (Lone et al. 1993). These developments have been interpreted as a shift from single season to bi-seasonal cultivation, with the emergence of rice as the dominant crop linked to more favourable summer growing conditions in Kashmir (Lone et al. 1993: 202-203). However, the diversity of botanical assemblages across sites in the valley seems to suggest at least some form of localised selection of crops. This may be reinforced through examination of stratified botanical remains from a conical pit at Qasim Bagh (Spate et al. 2017), where wheats dominated throughout the sequence dated ca. 2000-1400, with smaller proportions of broomcorn millet (Panicum miliaceum) and lentil. Barley and rice are entirely absent from the assemblage.

Rice dominates the Megalithic and NBPW phases at Semthan, before a shift to primarily barley and wheat during the Indo-Greek and Kushan periods (Lone et al. 1993). Barley and wheat together make up the largest proportion of crops during the Kushan period at Kanispur at nearly double the quantity of summer rice and millets (Pokharia et al. 2017). The returning dominance of winter wheat/barley may be ascribed to their higher calorific returns (Bates et al. 2017), as well as their suitability to cooler-dry conditions following the Megalithic period. Due to a lack of excavation data, it is unclear whether there was a form of population collapse, though fragmentary evidence suggests some form of "Iron Age" social reorganisation took place in Kashmir and regionally following 1000 BC (Yatoo 2012: 287-289). Climate or population factors aside, these reorganisations may have led to shifting of patterns of labour, better suited to flexible forms of agro-pastoralism incorporating wheat and barley, rather than the more centralised cultivation of rice on the valley floor.

Archaeobotanical remains from pre and early historic sites in Kashmir give insight into long term patterns of human adaptation to the ecology of the valley. The early barley and emmer wheat dominated phases at Kanispur and Gufkral may be evidence of the initial importation into the valley of aridity tolerant forms of cultivation more suited to the hilly northern regions of South Asia. Shifts towards wheat and rice cultivation may be driven by social or cultural factors as well as exploitation of the more fertile Jhelum alluvial soils and water availability in the valley. Proportional representation of botanical remains may be influenced by taphonomic and other predeposition factors, however the spatial and chronological variation of these remains across the valley allows some understanding of economic shifts as part of long term human-environment interaction in Kashmir. 


\subsubsection{Evidence for Pastoralism}

Mortality patterns and species composition in faunal assemblages from Gufkral indicate an economy based on hunting of wild animals during the Aceramic Neolithic period, with domestic sheep and goats representing only $5 \%$ of the total assemblage (Sharma 2013). By the Early Neolithic, domestic caprids represent $26 \%$ of the animal economy, with domestic cattle making up a further $18 \%$. These proportions increasing to 45 and $20 \%$ during the Late Neolithic. No faunal data has been published from either Burzahom or Kanispur, though preliminary reports indicate a significant hunting element at Burzahom during the Early Neolithic (Allchin and Allchin 1982: 112). Changes in these assemblages suggest an increasingly important pastoral component to the economy of Kashmir, though this development has been little examined other than Singh's (1963) attribution of some past deforestation on the flanks of the valley to Central Asian pastoralist groups.

With the exception of Singh's comments, there has been little consideration of the past impacts of transhumant grazing in Kashmir. Recent studies in the mountainous zones of Central Asia have situated pastoral groups as drivers of prehistoric crop exchange (Stevens et al. 2016; Spengler 2015), as well as pastoralist ecological practices and routes as laying the basis of the historic Silk Road networks between China, Central and South Asia (Frachetti et al. 2017). Stevens et al. (2016) have considered Kashmir as an important node in the spread of Chinese technologies and domesticates including stone fruits, millets and ground edged harvesters into northern South Asia, though the timing and mechanisms for this exchange are not yet articulated. The recent discovery of broomcorn millets at Qasim Bagh (Spate et al. 2017) seems to indicate that these exchanges likely took place through contact with pastoralist networks of exchange throughout Central and South Asia in the second millennium BCE. As well as their importance in developing these exchange networks, long term and flexible land use patterns by pastoral groups in Central Asia maybe important tools for understanding patterns of human resilience and environmental adaptation in the region (Spengler et al. 2013; Frachetti 2012). Due to the limited survey and excavation that has taken place in Kashmir, particularly at middle altitudes, detecting the presence of past patterns of pastoralism may be best approached through environmental records. Following the NCT concept for pastoralist modification of the landscape proposed by Spengler (2014), we may consider applicable markers for pastoralist modification of, and adaptation to, the Kashmir landscape in the past.

Though there has been no major research into past pastoral environmental impacts in Kashmir, modern ethnographic (Casimir and Rao 1985) and ecological (Mir et al. 2015; Ahmad et al. 2013; Dad and Khan 2010) studies have documented the impact of grazing of various intensities on vegetation communities distributed spatially and altitudinally across Kashmir. Through participant observation of seasonally migrating Bakharwal nomads, Casimir and Rao (1985) observe the cutting of corridors through mature Pinus forests on the northern slopes on the Pir Panjal at the southern pass into Kashmir (2500 m ASL) and exploitation of Poa and Chrysopogon grasses, as well as of white clover (Trifolium repens) and intensive gathering of various Poly- 
gonum, Chenopodium and Cerastium for both human and animal consumption. The suppression of Pinus stands assists in the propagation of these herbaceous taxa and may be considered one form of ecological niche construction by pastoralist groups. Propagation of T. repens and Plantago species are also associated with pastoral activity at the high altitude (3400 m ASL) meadow at Chandanvari (Casimir and Rao 1985: Table 3).

In pasturelands adjacent to the valley floor, near the modern city of Anantnag, Ahmad et al. (2013) analysed species composition at 12 sites subject to varying intensities of grazing. At ungrazed sites, the grass Bothriochloa pertusa dominated the species composition, while at moderate and heavily grazed sites, Cynodon dactylon was the dominant grass species. As grazing intensity increased, the Imporance Value Index (IVI) of these two grasses increase and a strong association between the two species was found at sites subject to overgrazing. At moderately grazed sites, Medicago lupilina is closely related to C. dactylon. Strong IVI values were also reported for Trifolium repens in relation to grazing, with evidence for colonisation by Plantago laceolata and P. majora at heavily grazed sites.

Mir et al. (2015) also recorded a strong correlation and dominance between $B$. pertusa and $C$. dactylon at three alpine pasture sites around Sonmarg in the east of Kashmir. These grasses along with Poa annua, Stipa siberica and Sambucus whightiana dominate IVI both before and after grazing at all three sites. Substantial to total declines in IVI of Rumex nepalensis and Rumex dentata after grazing at two of the sites may indicate the palatability of these taxa as forage plants. Similar taxa were associated with grazing at several high altitude sites studied by Dad and Khan (2010). Dad and Khan also note the colonisation of abandoned grazing campsites by nitrophilious Rumex nepalensis. All studies recorded a marked reduction in overall herbaceous diversity correlated with grazing intensity.

The viability of these taxa for reconstructing past pastoral practises is complicated by a number of factors. Declining Pinus or other arboreal forest pollen may be a proxy indicator of some form of land clearing, particularly if these changes can be separated from climatic effects. Micro-charcoal influxes may also be an informative indicator of forest clearing. Long range deposition of coniferous pollens may also have a masking effect on localised changes in forest communities. The primary taxa associated with grazing intensification in the above studies are all grasses whose pollens may not be separable from other species and may not be representative of grazing induced changes in the landscape. Despite these problems, wholesale advance of grass species as the expense of forest taxa may be a general indicator of pastoralist activities within the mountainous zones of Kashmir below the timber line. Of non-arboreal or grassland taxa, Trifolium and Medicago species associated with grazing are insect pollinated and not likely to be represented in environmental archives. Fluctuations in palatable Polygonum, Chenopodium species that may be propagated by pastoral actions may be good indicators of past grazing. More suitable may be wind pollinated Rumex species as these are closely related to grazing intensity in the above studies and are also early colonisers of grazed and disturbed land. Ruderal Plantago species may also be good indicators of gazing induced dis- 
Table 6.5 Potential pollen proxies for past grazing in Kashmir

\begin{tabular}{|c|c|c|c|}
\hline Forest taxa & Grasses & Herbaceous-palatable & Herbaceous-ruderal \\
\hline $\begin{array}{l}\text { Pinus wallachiana } \\
\text { Cedrus deodara } \\
\text { Abies pindrow } \\
\text { Fern understory }\end{array}$ & $\begin{array}{l}\text { Bothriochloa pertusa } \\
\text { Cynodon dactylon } \\
\text { Poa аппиа }\end{array}$ & $\begin{array}{l}\text { Polygonum sp. } \\
\text { Chenopodium } \mathrm{sp} . \\
\text { Rumex nepalensis } \\
\text { Rumex dentata }\end{array}$ & $\begin{array}{l}\text { Rumex nepalensis } \\
\text { Plantago lanceolata } \\
\text { Plantago majora }\end{array}$ \\
\hline
\end{tabular}

turbances. Table 6.5 summarises potential marker species for pastoralist activity in Kashmir.

\subsection{Conclusions}

\subsubsection{Discussion}

The above archaeological and environmental data have highlighted the potential for multi-proxy studies in understanding long term human-environment interaction and resilience in Kashmir. Current limitations to building on this framework include difficulties in undertaking new archaeological fieldwork, and the lack of finely resolved chronologies at singular sites and across the valley more generally. The lack of a well resolved sequence at the environmental cores from middle and high altitude grazing sites at Toshmaidan (Singh 1963) and Butapathri (Dodia 1983) complicates the detection of pastoral strategies in the past.

Despite the shortcomings of these records, early examination of settlement, archaeobotanical and environmental data indicates that past populations in Kashmir not only responded to climate changes beyond cycles of population expansion and collapse but undertook varying strategies to modify both social behaviour and the environment to allow for resilient responses to climatic deteriorations. Fluctuations in climate conditions may have been responded to by shifting patterns of summer/winter cultivation and differentiated usage of alluvial or foothill zones as adaptations to higher summer runoff or increased winter precipitation. We may see evidence of these shifts in the changing archaeobotanical assemblages of the Neolithic and Kushan periods (Pokharia et al. 2017; Spate et al. 2017; Lone et al. 1993).

Changes in agricultural land use may have also led to shifting patterns of settlement as well as an expansion of pastoralist exploitation of middle and high altitude pastures. Data from Yatoo's (2012) survey indicates a colonisation of mountain zones during the Kushan period, though this may have taken place earlier without leaving marked archaeological signatures. This pastoralist ecology may have allowed for engagement with other transhumant groups from around the mid-second millennium BC and intensified following the emergence of the historic Silk Roads (Frachetti et al. 2017). Connections with neighbouring Silk Road polities during the Kushan and Karkota periods, along with the centralisation of power under dynastic rule in the valley may 
have presented trade, technological and political means to mitigate the effects of climate change in the valley.

In contrast to previous notions of climate driven cycles of social expansion and collapse in Kashmir, we may take steps to examine long term patterns of resilience across differentiated landscapes and altitudinal zones in Kashmir. Detecting these responses and adaptations at local and regional scales presents the opportunity for new problem oriented and hypothesis testing fieldwork to take place in Kashmir, employing spatially and temporally suitable environmental and archaeological proxies and datasets.

\subsubsection{Future Prospects-Pari-Has}

In May 2017 a series of preliminary environmental soundings were taken at several sites across Pir Panjal flank of Kashmir. This sampling aims to detect anthropogenic change in the landscape at middle and higher altitudes, with a focus on grazing impacts. Much of this work focused on the Dodpathri area of Budgam district, a meadow zone within the montane forests on the east flank of the valley. Altitude in the area ranges from around 2500-2800 $\mathrm{m} \mathrm{ASL}$ and is situated below the passes to the higher pastures at Toshmaidan.

Pari-Has (Site D, Fig. 6.3) is a peat deposit situated upon a series of grazing terraces, within a wooded Abies-Pinus belt (Fig. 6.4). Two samples were taken up to a depth of $2 \mathrm{~m}$ using push cores. The first core, PH01, was only sampled to a depth of $1.2 \mathrm{~m}$, but this sample was favoured for further study due to possible contamination of the second sample. A sequence of peat-clay-peat was logged (Fig. 6.5), and three AMS dates from bulk organic material were returned from the base of the sample as well as below and above the peat-clay transitions (Table 6.6). The base of the sequence dates between 2330 and $2150 \mathrm{BP}$ whilst peat formation is arrested around $1900 \mathrm{BP}$, resuming around $750 \mathrm{BP}$ (Fig. 6.5). It is unclear whether the formation of clay bedding is a result of cool dry conditions, or wetter conditions transforming the peat bog to a small lake. The chronology of the formation and deposition of the peat-clay sequence seems to run contra to the general scheme of cold dry conditions in Kashmir for several centuries before 2000 BP, followed by a climatic amelioration of around 500 years (Agrawal 1992).

Low magnetic susceptibility (K) throughout the sample (Fig. 6.5) suggests the steady deposition of diamagnetic materials (Evans and Heller 2003). Previous mag-

Table 6.6 AMS dates from core PH01. Calibrations in Oxcal 4.2

\begin{tabular}{l|l|l|c|c|l}
\hline Lab & Lab code & Sample code & Depth $(\mathrm{mm})$ & RC age & Cal. BP $(2-\sigma)$ \\
\hline DirectAMS & D-AMS023859 & PH01-A1 & 490 & $832 \pm 26$ & $787-692$ \\
\hline DirectAMS & D-AMS023860 & PH01-C1 & 760 & $1948 \pm 49$ & $2002-1741$ \\
\hline DirectAMS & D-AMS023861 & PH01-C2 & 1150 & $2223 \pm 28$ & $2321-2153$ \\
\hline
\end{tabular}




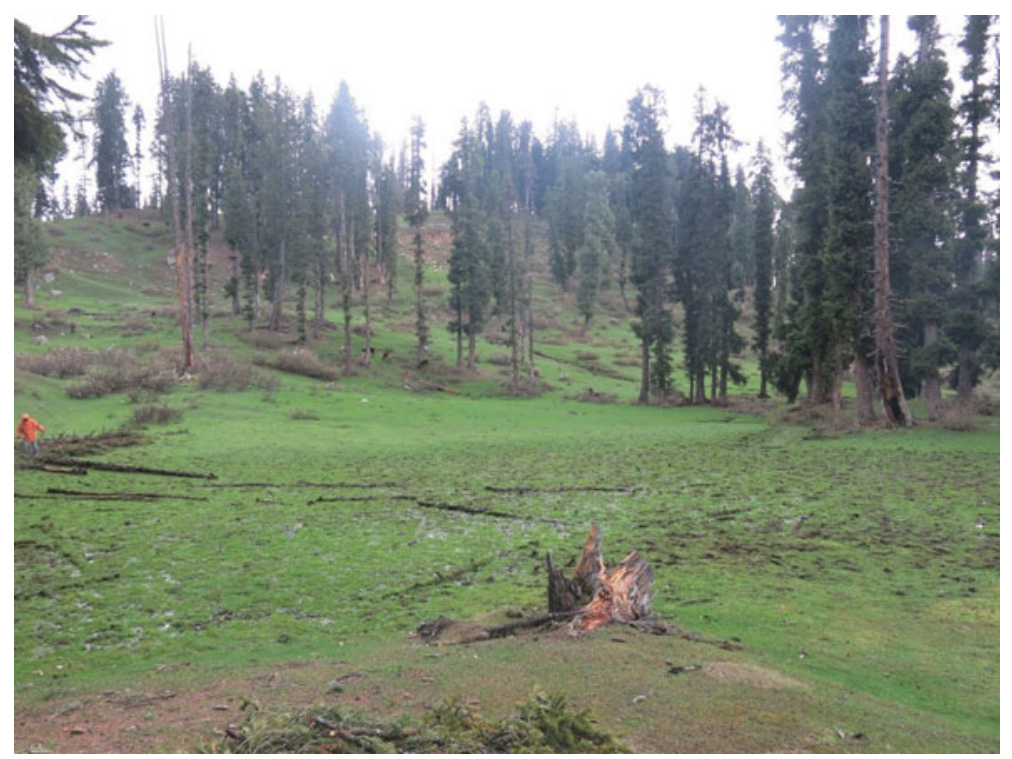

Fig. 6.4 Peat swamp at Pari-Has. View to northeast, showing slope up to grazing terrace

netic studies in Kashmir (Kusumgar et al. 1985) have used increased magnetic susceptibility of sediments as proxies for higher weathering and runoff of magnetite rich parent materials and thus wetter conditions, though this is generally reflected in mass magnetic susceptibility $(\chi)$ values higher than those of the Pari-Has record. Phadtare (2000) has correlated similar positive $\chi$ values comparable to Pari Has with warm wet conditions in a peat bog record from the Trans-Himalayas.

The sedimentary evidence suggests localised conditions within the mountain pasture belt around Dodpathri, beginning around the same time as the rise of the Kushan period in Kashmir. A single Kushan settlement has been reported around $5 \mathrm{~km}$ from the study site, and has been interpreted as part of a general movement by Kushan rulers to colonise and control mountain pastures and passes between Kashmir, the Kushan heartland of northern Pakistan and Silk Road trade routes into Tibet, China and Central Asia (Shah 2013). Aside from macro-botanical remains from the sites on the valley floor, little is known of the Kushan economy in Kashmir. The Pari-Has core has the potential for examining Kushan landscape management, pastoral and possible cultivation practices in mountain zones on the valley flanks. Prospects for further work include analysis of charcoal influx through the sediment column and large count numbers of herbaceous pollen grains, with a focus on indicator type 
Fig. 6.5 Stratigraphic section(left) and volume magnetic susceptibility (K-dimensionless in SI) (right) of core $\mathrm{PH} 01$

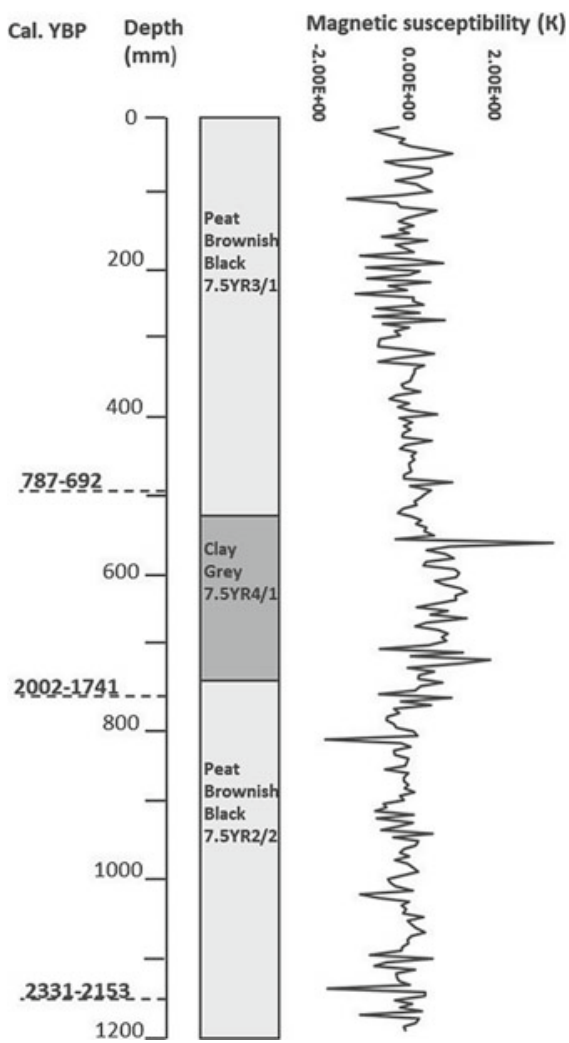

pollens discussed above. More closely controlled data relating to land and environmental management practices will allow for long term understanding of human resilience in Kashmir against the background of wider climate and social changes. Characterising the valley as an especially rich ecological niche will also help better link the valley with long scale cultural and political processes in adjacent centres of Central, East and South Asia.

Acknowledgements Sampling at Pari-Has took place as part of ongoing collaborative work between the Centre of Central Asian Studies (CCAS) at the University of Kashmir and the University of Sydney Central Asia Project. Author's 2017 travel to Kashmir and AMS dating was funded by a Carlyle Greenwell Research Grant (309236088) from the University of Sydney. Thanks is due to the two anonymous reviewers who took the time to read and comment on this manuscript. 


\section{References}

Agrawal, D. P. (1988). Palaeoclimatic data from Kashmir: A synthesis and some correlations. Proceedings of the Indian National Science Academy, 54A(3), 333-342.

Agrawal, D. P. (1992). Man and environment in India through ages: An interdisciplinary study of the Indian quaternary with focus on north-west. New Delhi: Books \& Books.

Agrawal, D. P., Dodia, R., Kusumgar, S., Nautiyal, V., \& Seth, M. (1989). Late quaternary environmental and archaeological changes in Kashmir. In K. Frifelt \& P. Sorsen (Eds.), South Asian Archaeology 1985 (pp. 271-276). London: Nordic Insitutue of Asian Studies.

Agrawal, D. P., \& Kharakwal, J. S. (2002). South Asian prehistory: A multidisciplinary study. New Delhi: Aryan Books International.

Ahmad, S., Dar, H. U., Dar, J. A., \& Majeedi, Z. M. (2013). Impact of varying disturbances on the structure and composition of grassland vegetation in Anantnag, Kashmir Himalayas. Proceedings of the International Academy of Ecology and Environmental Sciences.

Allchin, B., \& Allchin, R. (1982). The rise of civilization in India and Pakistan. London: Cambridge University Press.

Bamzai, P. (1994). Culture and political history of Kashmir (Vol. I). New Delhi: MD Publications.

Bandey, A. A. (2009). Prehistoric Kashmir: Archaeological history of Palaeolithic \& Neolithic cultures. New Delhi: Dilpreet Publishing House.

Bates, J., Petrie, C. A., \& Singh, R. N. (2018). Cereals, calories and change: Exploring approaches to quantification in Indus archaeobotany. Archaeological and Anthropological Sciences, 10(7), $1703-1716$.

Bhatt, D. K. (1978). Geological observations of the margs of Kashmir Valley, India. Himalayan Geology, 8, 769-783.

Boivin, N. L., Zeder, M. A., Fuller, D. Q., Crowther, A., Larson, G., Erlandson, J. M., et al. (2016). Ecological consequences of human niche construction: Examining long-term anthropogenic shaping of global species distributions. Proceedings of the National Academy of Sciences, 113(23), 6388-6396.

Casimir, M. J., \& Rao, A. (1985). Vertical control in the western Himalaya: Some notes on the pastoral ecology of the nomadic Bakrwal of Jammu and Kashmir. Mountain Research and Development, 5(3), 221-232.

Conningham, R., \& Sutherland, T. (1997). Dwellings or Granaries? The Pit Phenomenon of the Kashmir-Swat Neolithic. Man and Environment, 22(2), 29-34.

Costantini, L. (1981). The beginning of agriculture in the Kachi Plain: The evidence of Mehrgarh. In South Asian Archaeology.

Costantini, L. (2008). The first farmers in Western Pakistan: the evidence of the Neolithic agropastoral settlement of Mehrgarh. Pragdhara, 18, 167-178.

Dar, R. A., Romshoo, S. A., Chandra, R., \& Ahmad, I. (2014). Tectono-geomorphic study of the Karewa Basin of Kashmir Valley. Journal of Asian Earth Sciences, 92, 143-156.

D’Alpoim-Guedes, J., Lu, H., Li, Y., Spengler, R. N., Wu, X., \& Aldenderfer, M. S. (2014). Moving agriculture onto the Tibetan plateau: The archaeobotanical evidence. Archaeological and Anthropological Sciences, 6(3), 255-269.

Dad, J. M., \& Khan, A. B. (2010). Floristic composition of an alpine grassland in Bandipora, Kashmir. Grassland Science, 56(2), 87-94.

Das, B. K., Birgit-Gaye, \& Malik, M. A. (2010). Biogeochemistry and paleoclimate variability during the Holocene: a record from Mansar Lake, Lesser Himalaya. Environmental Earth Sciences, 61, 565-574. https://doi.org/10.1007/s12665-009-0366-0 .

De Terra, H., \& Paterson, T. T. 2003 [1939]. The Ice Age in the Indian Subcontinent and Associated Human Cultures: With Special Reference to Jammu, Kashmir, Ladakh, Sind, Liddar \& Central and Peninsular India. New Delhi: Aryan Books.

Demske, D., Tarasov, P. E., Wünnemann, B., \& Riedel, F. (2009). Late glacial and Holocene vegetation, Indian monsoon and westerly circulation in the Trans-Himalaya recorded in the lacus- 
trine pollen sequence from Tso Kar, Ladakh, NW India. Palaeogeography, Palaeoclimatology, Palaeoecology, 279(3), 172-185.

Dodia, R. (1983). Palynological investigations on the Kashmir valley India (Unpublished Ph.D. thesis). Gujarat University, Ahmedabad.

Ellis, E., Magliocca, N., Stevens, C., \& Fuller, D. (2017). Evolving the Anthropocene: linking multilevel selection with long-term social-ecological change. Sustainability Science, 16(1), 119-128.

Evans, M., \& Heller, F. (2003). Environmental magnetism: Principles and applications of enviromagnetics (Vol. 86). Academic Press.

Faulseit, R. K. (Ed.). (2015). Beyond collapse: Archaeological perspectives on resilience, revitalization, and transformation in complex societies. Carbondale: South Illinois University Press.

Frachetti, M. (2012). Multiregional emergence of mobile pastoralism and nonuniform institutional complexity across Eurasia. Current Anthropology, 53(1), 2-38.

Frachetti, M., Smith, C. E., Traub, C. M., \& Williams, T. (2017). Nomadic ecology shaped the highland geography of Asia's Silk Roads. Nature, 543(7644), 193-198.

Goldberg, P., \& Macphail, R. (2006). Practical and theoretical geoarchaeology. Malden, MA, Oxford: Blackwell Publishing.

Harris, D. (2010). Origins of agriculture in Western Central Asia. Philadelphia: University of Pennsylvania Museum.

Husain, M. (2008). Systematic geography of Jammu and Kashmir. Jaipur: Rawat Publications.

Kak, R. C. (1933). Ancient monuments of Kashmir. London: The Indian Society.

Kaul, A. K. (2014). Studies in geography of Jammu and Kashmir. Jaipur: Rawat Publications.

Krishnamurthy, R. V., DeNiro, M. J., \& Pant, R. K. (1982). Isotope evidence for Pleistocene climatic changes in Kashmir, India. Nature, 298(5875), 640-641.

Kusumgar, S., Agrawal, D. P., Juyal, N., \& Sharma, P. (1986). Palaeosols within loess: Dating palaeoclimatic events in Kashmir. Radiocarbon, 28(2a), 561-565.

Laland, K. N., \& O'Brien, M. J. (2010). Niche construction theory and archaeology. Journal of Archaeological Method and Theory, 17(4), 303-322.

Leipe, C., Demske, D., Tarasov, P. E., Wünnemann, B., Riedel, F., \& Members, H. P. (2014). Potential of pollen and non-pollen palynomorph records from Tso Moriri (Trans-Himalaya, NW India) for reconstructing Holocene limnology and human-environmental interactions. Quaternary International, 348, 113-129.

Lone, F. A., Khan, M., \& Buth, G. M. (1993). Palaeoethnobotany Plants and Ancient Man in Kashmir. Amsterdam: A.A. Balkema.

Mani, B. R. (2000). Excavations at Kanispur: 1998-99 (District Baramulla Kashmir). Journal of Interdisciplinary Studies in History and Archaeology, 10, 1-21.

McAnany, P. A., \& Yoffee, N. (Eds.). (2009). Questioning collapse: Human resilience, ecological vulnerability, and the aftermath of empire. Cambridge University Press.

Middleton, G. D. (2012). Nothing lasts forever: Environmental discourses on the collapse of past societies. Journal of Archaeological Research, 20(3), 257-307.

Miehe, G., Miehe, S., Kaiser, K., Reudenbach, C., Behrendes, L., Duo, L., et al. (2009). How old is pastoralism in Tibet? An ecological approach to the making of a Tibetan landscape. Palaeogeography, Palaeoclimatology, Palaeoecology, 276(1), 130-147.

Miller, N. F. (1999). Agricultural development in western Central Asia in the Chalcolithic and Bronze Ages. Vegetation History and Archaeobotany, 8(1), 13-19.

Mir, F. A., Bhat, G. A., Sheer, B. A., \& Khan, A. G. (2015). Impacts of seasonal livestock grazing on plant community features: a case study on grazing pastures at Sonamarg area in Kashmir Himalaya. Journal of Agricultural Sciences, 10(1).

Mitra, D. (Ed.). (1983). Indian archaeology 1980-81 a review (pp. 21-26). Calcutta: Archaeological Survey of India.

Murphy, C. A., \& Fuller, D. Q. (2016). Production in India: South Asian entanglements of domestication. In A companion to South Asia in the past (p. 344).

Pant, R. K., Gaillard, C., Nautiyal, V., Gaur, G. S., \& Shali, S. L. (1982). Some new lithic and ceramic industries from Kashmir. Man and Environment, 6, 37-40. 
Petrie, C. A., Singh, R. N., Bates, J., Dixit, Y., French, C. A. I., Hodell, D. A., et al. (2017). Adaptation to variable environments, resilience to climate change: Investigating in Indus Northwest India. Current Anthropology, 58(1),1-30.

Phadtare, N. R. (2000). Sharp decrease in summer monsoon strength 4000-3500 cal yr B.P. in Central Higher Himalaya of India based on pollen evidence from alpine peat. Quaternary Research, 53, 122-129.

Pokharia, A., Mani, B., Spate, M., Betts, A., Srivastava, A. (2017). Early Neolithic Agriculture (2700-2000 BC) and Kushan period developments (AD 100-300): Macrobotanical evidence from Kanispur in Kashmir, India. Vegetation History and Archaeobotany. https://doi.org/10.1007/ s00334-017-0645-8.

Possehl, G. L. (2002). The Indus civilization: A contemporary perspective. Walnut Creek: AltaMira.

Qazi, S. A. (2005). Systematic geography of Jammu and Kashmir. New Delhi: APH Publishing House.

Rawat, S., Gupta, A. K., Sangode, S. J., Srivastava, P., \& Nainwal, H. C. (2015). Late PleistoceneHolocene vegetation and Indian summer monsoon record from the Lahaul, Northwest Himalaya, India. Quaternary Science Reviews, 114, 167-181.

Scott, J. C. (2017). Against the grain: A deep history of the earliest states. New Haven \& London: Yale University Press.

Shah, M. A. (2013). Early historic archaeology in Kashmir: An appraisal of the Kushan Period. Bulletin of the Deccan College Research Institute, 72, 213-224.

Shali, S. L. (2001). Settlement pattern in relation to climatic changes in Kashmir. New Delhi: OM Publications.

Sharma, A. K. (2013). Excavations at Gufkral (Jammu and Kashmir). New Delhi: B.R. Publishing House.

Sidhu, G. S., \& Surya, J. N. (2014). Soils of North-Western Himalayan eco-system and their land use, constraints, productivity potentials and future strategies. Agropedology, 24(01), 1-19.

Singh, G. (1963). A preliminary survey of post-glacial vegetation history in the Kashmir Valley. Paleobotanist, 12(1), 73-108.

Singh, G., \& Agrawal, D. P. (1976). Radiocarbon evidence for early deglaciation in north-western Himalaya, India. Nature, 260, 232.

Spate, M., Zhang, G., Yatoo, M., \& Betts, A. (2017). New evidence for early 4th millennium BP agriculture in the Western Himalayas: Qasim Bagh, Kashmir. Journal of Archaeological Science: Reports, 11, 568-577.

Spengler, R. N. (2014). Niche dwelling vs niche construction: Landscape modification in the bronze and iron ages of central Asia. Human Ecology, 42(6), 813-821.

Spengler, R. N. (2015). Agriculture in the Central Asian Bronze Age. Journal of World Prehistory, 28(3), 215-253.

Spengler, R. N., Frachetti, M. D., \& Fritz, G. J. (2013). Ecotopes and herd foraging practices in the steppe/mountain ecotone of Central Asia during the Bronze and Iron Ages. Journal of Ethnobiology, 33(1), 125-147.

Stevens, C. J., Murphy, C., Roberts, R., Lucas, L., Silva, F., \& Fuller, D. Q. (2016). Between China and South Asia: A middle Asian corridor of crop dispersal and agricultural innovation in the Bronze Age. The Holocene, 26(10), 1541-1555.

Thapar, B. K. (Ed.). (1980). Indian archaeology 1976-77: A review (pp. 19-75). Calcutta: Archaeological Survey of India.

Thomas, K., \& Cartwright, C. (2010). The bioarchaeological remains from Sheri Khan Tarakai: Environments, resources and subsistence. In C. Petrie (Ed.), Sheri Khan Tarakai and early village life on borderlands of northwest Pakistan (pp. 305-342). Oxford: Oxbow Books.

Trivedi, A., \& Chauhan, M. S. (2009). Holocene vegetation and climate fluctuations in northwest Himalaya, based on pollen evidence from Surinsar Lake, Jammu region, India. Journal of the Geological Society of India, 74(3), 402-412.

Vishnu-Mittre. (1966). Some aspects of concerning pollen analytical investigations in the Kashmir valley. The Palaeobotanist, 15, 157-175. 
Vishnu-Mittre, K. S., \& Sharma, B. D. (1966). Studies of postglacial vegetational history from the Kasmir Valley 1. Haigam Lake. Palaeobotanist, 15, 185-212.

Yatoo, M. A. (2005). Archaeological Explorations of Sopore and Bandipora Tehsils in District Baramulla Kashmir (Unpublished M.Phil. thesis). University of Kashmir, Srinagar.

Yatoo, M. A. (2012). Characterising material culture to determine setlement patterns in North West Kashmir (Unpublished Ph.D. thesis). University of Leicester.

Yatoo, M. A., \& Bandey, A. A. (2014). Relations of Neolithic Kashmir with South and Central Asia: A comparative analysis of material culture from new sites in Kashmir. Journal of Central Asian Studies, 26, 37-46.

Young, R. (2003). Agriculture and pastoralism in the Late Bronze and Iron Age, North West Frontier Province, Pakistan. Oxford: BAR International Series.

Open Access This chapter is licensed under the terms of the Creative Commons Attribution 4.0 International License (http://creativecommons.org/licenses/by/4.0/), which permits use, sharing, adaptation, distribution and reproduction in any medium or format, as long as you give appropriate credit to the original author(s) and the source, provide a link to the Creative Commons license and indicate if changes were made.

The images or other third party material in this chapter are included in the chapter's Creative Commons license, unless indicated otherwise in a credit line to the material. If material is not included in the chapter's Creative Commons license and your intended use is not permitted by statutory regulation or exceeds the permitted use, you will need to obtain permission directly from the copyright holder. 